(Previously Prace Naukowe Instytutu Gornictwa Politechniki Wroclawskiej, ISSN 0370-0798)

ISSN 2300-9586 (print)

ISSN 2353-5423 (online)

\title{
THE EXPERIMENTAL STUDY OF COMPACTION PARAMETERS AND ELASTIC AFTER-EFFECT OF FINE FRACTION RAW MATERIALS
}

\author{
Kostiantyn BAIUL ${ }^{1}$, Aleksander KHUDYAKOV ${ }^{1}$, \\ Sergii VASHCHENKO ${ }^{1}$, Pavlo KROT ${ }^{2 *}$, Nataliia SOLODKA ${ }^{3}$ \\ 1 Technological Equipment and Control Systems Department, Z.I. Nekrasov Iron and Steel Institute of Na- \\ tional Academy of Sciences of Ukraine, 1 Acad. Starodubov sq., 49005 Dnipro, Ukraine \\ ${ }^{2}$ Faculty of Geoengineering, Mining and Geology, Wroclaw University of Science and Technology, $15 \mathrm{Na}$ \\ Grobli st., 50-421 Wroclaw, Poland \\ ${ }^{3}$ Information System Department, State Higher Educational Institution "Ukrainian State University \\ of Chemical Technology", 8 Gagarin Ave., 49005 Dnipro, Ukraine
}

\begin{abstract}
Mining and metallurgical enterprises generate a significant amount of secondary raw material resources having small-fractions (below $3 \mathrm{~mm}$ ). A significant volume of these materials can be returned into the production process by the use of the briquetting method. The quality of briquettes, in particular, their strength, is significantly affected by a phenomenon called elastic after-effect. For a theoretical study of the elastic after-effect influence on the quality of the briquettes, taking into account the pressing tool configuration, experimental data are obtained for three materials (peat, kaolin and manganese concentrate). Results are in creating the analytical relations (regression models) having enough high accuracy to describe the dependence of compaction coefficient, elastic after-effect, density and elastic heave (decompaction) on an external pressure in the compaction machine.
\end{abstract}

Keywords: small fractions, raw materials, compaction coefficient, elastic after-effect, density, pressure

* Corresponding author: pavlo.krot@pwr.edu.pl (Pavlo Krot)

doi: $10.37190 / \mathrm{msc} 202701$ 


\section{INTRODUCTION}

A lot of industrial processes in mining, metallurgy and energetics resulted in large quantities of waste small fractions. At the same time, many wastes from the mining and metallurgical industries are valuable raw materials in terms of their chemical composition, which can be reused in technological plants after certain processing. To prove the importance of waste small fractions processing, the following facts can be highlighted.

In the coal industry, existing mining methods are characterized by the increased amount of coal fines with approximately $12 \%$ of tonnage classified as fines that are accumulated in slurry ponds or discard dumps (Henning et al. 2018). At the same time, coal sludge and dust, depending on the field, have a calorie content of 3500 to $7500 \mathrm{kcal} / \mathrm{kg}$ with an ash content of 13 to $40 \%$. This allows them to be attributed to energetically valuable secondary raw materials.

A similar situation arises with small fractions of brown coal (Kinoshita et al. 2010), coke fines (Al-Haj Ibrahim et al. 2014) and hydrolytic lignin (Rabinovich 2014; Kieush et al. 2019), which may also be used as fuels.

Some types of metallurgical waste are composed of about 40-70\% iron, manganese, alloying metals, there is waste containing calcium and magnesium oxides up to $60 \%$. They, in chemical composition, is close to mineral raw materials (Ramachandra Rao, 2006).

In the aluminium production, a significant amount of red mud is formed, which itself is a valuable raw material - the content of iron oxides up to $45 \%$, alumina up to $16-18 \%$ and some rare earth metals (Rai et al. 2012).

In the ferroalloys industry, at the stages of ore mining, charge preparation and smelting of ferroalloys, a lot of fine raw materials are formed (Rösler et al. 2016; Zhdanov et al. 2015). When fractionating ferroalloys, before shipment to consumers, up to about $10 \%$ of fines from 0 to $5 \mathrm{~mm}$ are formed. Dust from gas cleaning systems generated in large volumes also contains a significant amount of valuable components.

There are a lot of similar examples of technological processes where significant volumes of small-fraction secondary resources are formed in the mining and metallurgical industries. What unites these materials is that in order to return them to the technological cycle of production, as a rule, they require agglomeration.

Despite the currently well-developed pelletizing and agglomeration methods, a number of fine-grained wastes cannot be agglomerated by such methods. This may be due to the technological peculiarities of their use, chemical and mechanical properties of materials, etc. In this case, an alternative way to obtain a lumpy product may be briquetting.

As practice shows, when developing technologies and equipment for briquetting, in addition to the size of components and chemical composition of the mixture, the compaction value and energy-power parameters of the pressing process, one should take into account the phenomenon of elastic after-effect in briquettes. 
Mechanism of elastic after-effect consists of the elastic restoration of particle contacts after relieving pressure. In processes of briquettes production from small fractional raw materials, this phenomenon leads to a decrease in density of briquettes and can have a negative impact on their quality (Swietochowski et al. 2016; Križan et al. 2009; Davies et al. 2013), which may occur in the form of briquettes cracking and delamination (see Fig. 1).
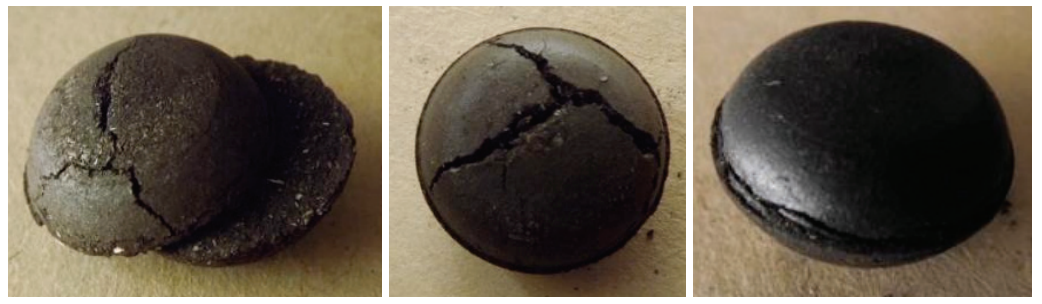

Fig. 1. Defects in briquettes caused by the elastic after-effect

Development of theoretical statements explaining the mechanism of this phenomenon and development of experimental and analytical methods for assessing its impact on the quality of briquettes have scientific and practical importance.

Formation of a method for assessing and minimizing the negative impact of elastic after-effect on the briquettes characteristics will complement the methods previously created for determining rational parameters of briquetting technology and equipment (Bayul 2012; Khudyakov et al. 2018; Vashchenko et al. 2019).

To create and develop a method for predicting and evaluating the impact of elastic after-effect on briquettes quality, it is necessary to have practical data on the relationship between compaction parameters and subsequent elastic expansion of real raw materials.

Therefore, the purpose of this work is to obtain and analyze experimental data on the parameters of compaction and elastic expansion of some representative samples of fine materials that are processed using briquetting method on an industrial scale press.

\section{TESTING MATERIALS}

For the experimental studies, the following materials are used: peat, kaolin, and manganese concentrate. The criterion for namely these materials selection is a set of physical and mechanical characteristics, that determine their varying degrees of sensitivity to externally applied forces.

Peat has a low bulk density, fibrous, hygroscopic structure of particles with significant elasticity. This makes peat sensitive to changes in technological parameters of 
briquetting. That is why it accepted in this work as a material for which effect of elastic after-effect on properties of briquettes will be most pronounced.

Kaolin has such physical and mechanical properties as hydrophilicity, dispersion, plasticity, which determine the conditions of its processing. Kaolin considered to be a good briquetting material, it is quite sensitive to the combination of its moisture content and compaction pressure. This allows optimizing the choice of power pressing mode. To achieve high-quality briquettes at the optimum ratio of moisture, high pressures are not required.

Manganese concentrate has a high bulk density and significant compressive strength. When pressed in order to obtain briquettes with required characteristics, an increase in pressing force is necessary.

Thus, selected materials have significant differences in properties and belong to different categories according to their ability to compaction. Such a choice makes it possible to consider the results of research as fair for a wide range of similar materials.

\section{EXPERIMENTAL PROCEDURE}

Selected materials are screened to a fraction of $<3 \mathrm{~mm}$. As shows a practical experience of briquetting of fine fraction materials, such a fraction is most favourable for obtaining model samples of small volumes. For the materials thus prepared, the main physical and mechanical characteristics determined, which are represented in Table 1.

Table 1. Physical and mechanical characteristics of the studied materials

\begin{tabular}{|l|c|c|c|}
\hline \multirow{2}{*}{ Material characteristics } & \multicolumn{3}{c|}{ Material } \\
\cline { 2 - 4 } & Peat & Kaolin & $\begin{array}{c}\text { Manganese } \\
\text { concentrate }\end{array}$ \\
\hline Moisture $W, \%$ & 14.25 & 1.05 & 15.9 \\
\hline Bulk density, $\rho_{\text {bulk }}, \mathrm{g} / \mathrm{cm}^{3}$ & 0.397 & 0.912 & 1.090 \\
\hline The hardness of the particles on the Mohs scale & $\approx 2$ & $2-2.5$ & $\approx 3-5$ \\
\hline True (pycnometric) density $\rho_{\text {pycn }}, \mathrm{g} / \mathrm{cm}^{3}$ & $1.0-1.2$ & $2.35-2.42$ & $3.0-3.5$ \\
\hline External friction angle $\varphi^{\circ}$ & 44.0 & 33.0 & 40.83 \\
\hline External friction coefficient $f_{1}$ & 0.96 & 0.64 & 0.87 \\
\hline Angle of repose $\varphi_{0},{ }^{\circ}$ & 23.56 & 35.42 & 35.0 \\
\hline Internal friction coefficient $f_{2}$ & 0.44 & 0.71 & 0.70 \\
\hline
\end{tabular}

For experiments, we used a hydraulic press with a pressing force up to $100 \mathrm{kN}$, a steel cylindrical mould with a matrix channel diameter of $30.1 \mathrm{~mm}$ and punches with flat ends. The scheme of a laboratory unit based on the hydraulic press is represented in Fig. 2.

Briquettes pressing from accepted materials have been carried out at the pressure values $p_{i}$ corresponding to a range of $10-100 \mathrm{MPa}$ with a step of $\Delta p 10 \mathrm{MPa}$. The range 
from 0 to $10 \mathrm{MPa}$ was not taken into account during the experiments. It corresponds to the initial stage of compaction with structural deformations predominance, including redistribution of particles and active air expulsion. At this stage, the material is not yet formed into a fully compacted briquette without large particles losing. Measurement of its geometrical parameters is difficult, gives a large error and from a practical point of view does not represent significant interest. To ensure the accuracy of the experimental data for each pressure point $p_{i}$, pressing was repeated at least seven times. Smallest and largest values of recorded indicators were not taken into account in the experimental data processing. Only five values $p_{i}$ were taken into account for each level of pressure. Thus, an array of experimental data is formed on the basis of 150 experimental samples (10 levels of pressure $\times 5$ experiments at each value of pressure $\times 3$ types of materials).

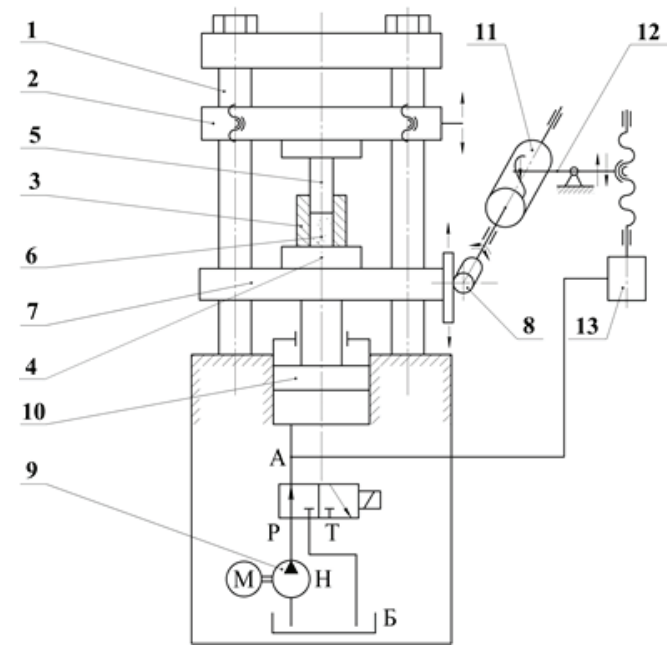

Fig. 2. Scheme of the laboratory unit based on a hydraulic press, used for small-fractional materials compaction parameters study:

1 - column, 2 - upper traverse, 3 - press mould, 4 - lower punch, 5 - upper punch,

6 - compressible material, 7 - lower traverse, 8 - transmission mechanism with shrinkage gauge,

9 - pump, 10 - hydraulic cylinder, 11 - recorder, 12 - pen of the recorder, 13 - pressure transducer

Compaction process measurement scheme shown in Fig. 3a, b. A portion of studied compressible material loaded into press mould 3 and placed on lower traverse 7 (Table) of the press with a pre-installed lower punch 4, then installed upper punch 5. On column 1 of the press, shrinkage gauge 8 of compressible (pressed) material is mounted, coupled with a movable lower traverse 7 . When pressure increases from $0 \mathrm{MPa}$ to a predetermined value $p_{i}$, probe of shrinkage gauge moves by displacement of punches $H_{u s . i}$. After the pressure released, its final position $H_{k i}$ recorded with an accuracy of $0.05 \mathrm{~mm}$. This value allows determining height $h_{0 i}$ of compressible material 6 (briquette), which is in press mould 3 under pressure: 


$$
h_{0 . i}=H_{0 . i}-H_{k . i},
$$

where $H_{0 . i}$ - position of gauge probe for a given pressure in absence of material in the press mould; $H_{1 . i}$ - position of gauge probe in experiments with material (see. Fig. 3a).

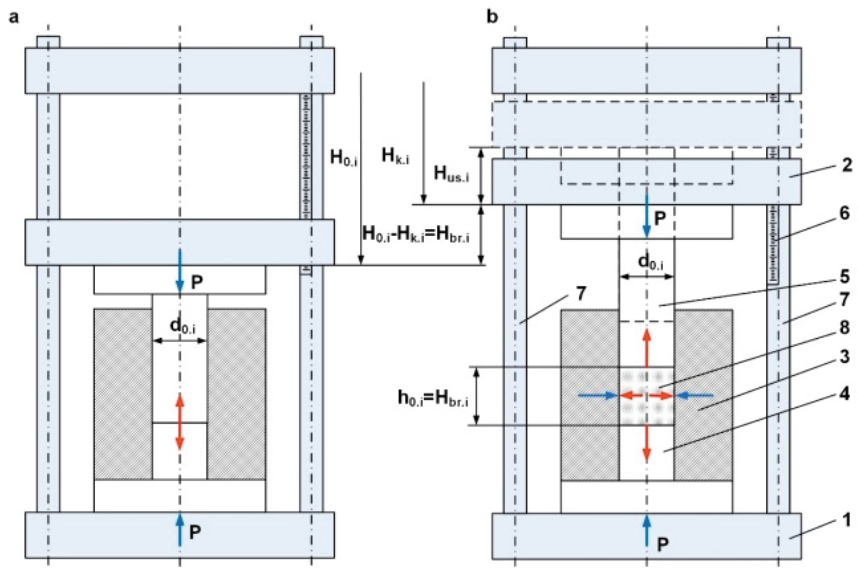

Fig. 3. Scheme for material compaction parameters determining: a - press tool under load in the absence of material in press mould, $\mathrm{b}$ - press tool during material compaction; 1 - column, 2 - upper traverse, 3 - press mould, 4 - lower punch, 5 - upper punch, 6 - compressible material, 7 -lower traverse, 8 - transmission mechanism shrinkage gauge

In this paper, it is assumed that elements of a pressing tool are absolutely rigid. This assumption is quite reasonable for small values of applied force and stresses and can be accounted by the addition of elastic deformations of mould and punches. Thus, the diameter of briquette $d_{0 . i}$, which is under pressure in the mould, is equal to the diameter of the matrix channel $-30.1 \mathrm{~mm}$, according to measurements. After removing briquettes from the press mould, their linear geometrical parameters were measured - height $h_{1 . i}$, diameter $d_{1 . i}$ (accuracy $0.05 \mathrm{~mm}$ ) and weight $m_{b r . i}$ (accuracy $0.05 \mathrm{~g}$ ).

Values of briquette volume $V_{0 . i}$, which is in the press mould under pressure, and $V_{1 . i}$ after releasing pressure and removing it from the press mould are calculated as:

$$
\begin{aligned}
& V_{0 . i}=\frac{\pi d_{0 . i}^{2}}{4} \cdot h_{0 . i}, \\
& V_{1 . i}=\frac{\pi d_{1 . i}^{2}}{4} \cdot h_{1 . i},
\end{aligned}
$$

where $h_{0 . i}, d_{0 . i}$ - briquette height and diameter in the press mould under action of pressure; $h_{1 . i}, d_{1 . i}$ - briquette height and diameter after relieving pressure and removing it from the press mould. Then, the compaction factor: 


$$
K_{y, i}=\frac{\rho_{\text {br.i }}}{\rho_{\text {bulk }}}=\frac{V_{\text {bulk }}}{V_{0 . i}}=\frac{m_{b r . i} / \rho_{\text {bulk }}}{\left(\pi d_{0}^{2} / 4\right) h_{0 . i}}
$$

and elastic after-effect:

$$
\delta_{V . i}=\frac{V_{1 . i}-V_{0 . i}}{V_{0 . i}} \cdot 100 \% .
$$

Briquette density $\rho_{b r .0 . i}$ under pressure and $\rho_{b r .1 . i}$ after extraction from the press:

$$
\begin{gathered}
\rho_{b r .0 . i}=\frac{4 m_{b r . i}}{\pi d_{0 . i}^{2} h_{0 . i}}, \\
\rho_{b r .1 . i}=\frac{4 m_{b r . i}}{\pi d_{1 . i}^{2} h_{1 . i}} .
\end{gathered}
$$

\section{EXPERIMENTAL RESULTS AND DISCUSSION}

Data obtained in experiments are grouped into an array (Table 2) and graphically represented in Figs. 4-6 with corresponding approximations. The accuracy of the approximation is estimated by the coefficient of determination $R^{2}$. Approximating equations are chosen in such a way that the $R^{2}=0.70-0.99$. Figure 4 shows experimental graphs approximated by power type equations, describing the functional relationship of pressure and compaction coefficient.
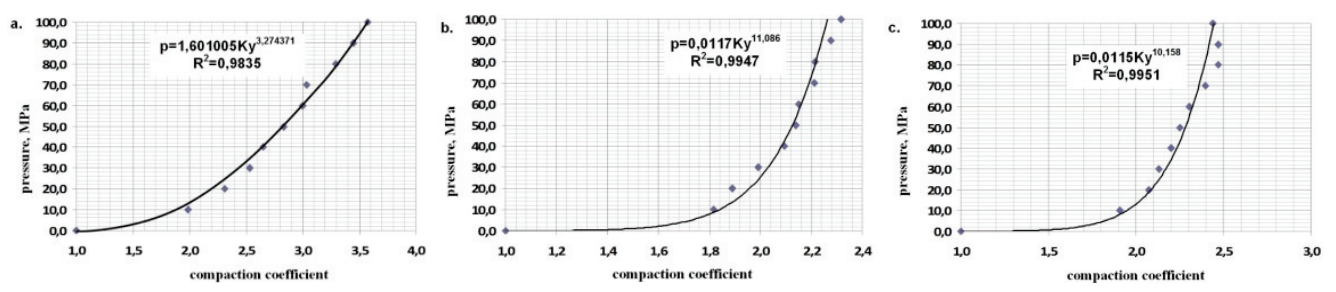

Fig. 4. Dependencies of compaction coefficient on pressure: $\mathrm{a}$ - peat, $\mathrm{b}$ - kaolin, $\mathrm{c}$ - manganese concentrate

Trend lines allow representing the nature and difference of investigated materials in resistance to compression. Approximation equations in Fig. 4 and in Table 3 can be used to calculate the magnitude and distribution of stress in briquettes.

Figure 5 shows graphical relations, characterizing the relationship between elastic after-effect $\delta_{V . i}$ and pressure $p_{i}$. 

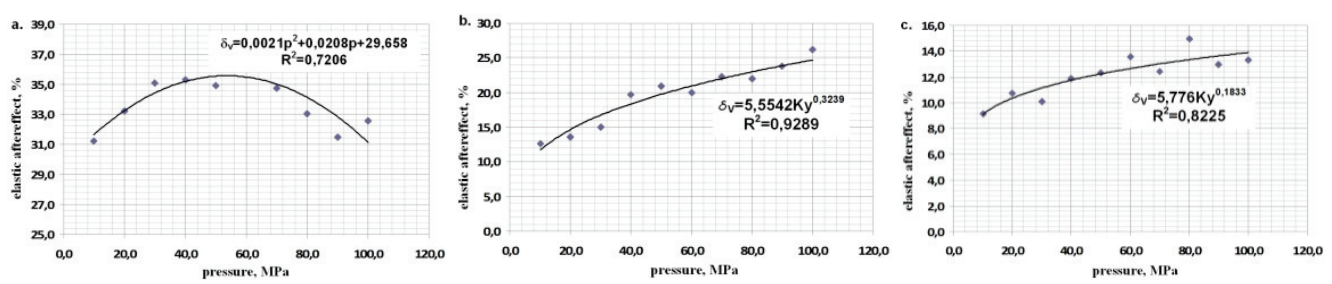

Fig. 5. Dependence of elastic after-effect on pressure:

$\mathrm{a}$ - peat, $\mathrm{b}$ - kaolin, $\mathrm{c}$ - manganese concentrate

Table 2. Experimental data on compaction of peat, kaolin and manganese concentrate

\begin{tabular}{|c|c|c|c|c|c|}
\hline$p_{i}, \mathrm{MPa}$ & $K y_{i}$ & $\delta_{V . i}, \%$ & $\rho_{b r .0 . i}, \mathrm{~g} / \mathrm{cm}^{3}$ & $\rho_{b r .1 . i}, \mathrm{~g} / \mathrm{cm}^{3}$ & $\Delta \rho_{b r .1 . i}, \mathrm{~g} / \mathrm{cm}^{3}$ \\
\hline \multicolumn{6}{|c|}{ Peat } \\
\hline 10 & 1.99 & 31.21 & 0.79 & 0.60 & 0.19 \\
\hline 20 & 2.31 & 33.22 & 0.91 & 0.68 & 0.23 \\
\hline 30 & 2.53 & 35.09 & 1.00 & 0.74 & 0.26 \\
\hline 40 & 2.65 & 35.28 & 1.05 & 0.78 & 0.27 \\
\hline 50 & 2.83 & 34.93 & 1.12 & 0.83 & 0.29 \\
\hline 60 & 3.00 & 37.13 & 1.19 & 0.87 & 0.32 \\
\hline 70 & 3.03 & 34.72 & 1.20 & 0.89 & 0.31 \\
\hline 80 & 3.29 & 33.04 & 1.31 & 0.98 & 0.32 \\
\hline 90 & 3.45 & 31.50 & 1.37 & 1.04 & 0.33 \\
\hline 100 & 3.57 & 32.54 & 1.42 & 1.07 & 0.35 \\
\hline \multicolumn{6}{|c|}{ Kaolin } \\
\hline 10 & 1.82 & 12.62 & 1.66 & 1.47 & 0.19 \\
\hline 20 & 1.89 & 13.60 & 1.72 & 1.52 & 0.21 \\
\hline 30 & 1.99 & 15.03 & 1.82 & 1.58 & 0.24 \\
\hline 40 & 2.09 & 19.72 & 1.91 & 1.60 & 0.31 \\
\hline 50 & 2.14 & 20.90 & 1.95 & 1.61 & 0.34 \\
\hline 60 & 2.15 & 19.96 & 1.96 & 1.63 & 0.33 \\
\hline 70 & 2.21 & 22.22 & 2.02 & 1.65 & 0.37 \\
\hline 80 & 2.21 & 21.96 & 2.02 & 1.66 & 0.36 \\
\hline 90 & 2.28 & 23.80 & 2.08 & 1.68 & 0.40 \\
\hline 100 & 2.32 & 26.21 & 2.11 & 1.67 & 0.44 \\
\hline \multicolumn{6}{|c|}{ Manganese concentrate } \\
\hline 10 & 1.91 & 9.17 & 2.08 & 1.90 & 0.17 \\
\hline 20 & 2.07 & 10.72 & 2.26 & 2.04 & 0.22 \\
\hline 30 & 2.13 & 10.10 & 2.32 & 2.11 & 0.21 \\
\hline 40 & 2.20 & 11.85 & 2.40 & 2.15 & 0.25 \\
\hline 50 & 2.25 & 12.34 & 2.45 & 2.18 & 0.27 \\
\hline 60 & 2.30 & 13.55 & 2.51 & 2.21 & 0.30 \\
\hline 70 & 2.40 & 12.43 & 2.52 & 2.24 & 0.28 \\
\hline 80 & 2.47 & 14.95 & 2.59 & 2.26 & 0.34 \\
\hline 90 & 2.47 & 12.97 & 2.59 & 2.30 & 0.30 \\
\hline 100 & 2.44 & 13.34 & 2.66 & 2.34 & 0.31 \\
\hline
\end{tabular}


Table 3. The results of the approximation

of experimental data describing the $p=f(K y)$ relation

\begin{tabular}{|l|c|c|}
\hline \multicolumn{1}{|c|}{ Material } & Approximation equation & $R^{2}$ \\
\hline Peat & $p=1.601005 \times K y^{3.274371}$ & 0.98 \\
\hline Kaolin & $p=0.0117 \times K y^{11.086}$ & 0.99 \\
\hline Manganese concentrate & $p=0.0115 \times K y^{10.158}$ & 0.99 \\
\hline
\end{tabular}

For peat (see Fig. 5a), dependence curve $\delta_{V}=f(p)$ described with sufficient accuracy by the second-degree polynomial. Value of $\delta_{V}$ gradually increases in the range up to $50 \mathrm{MPa}$. According to curve $p=f(K y)$ that characterizing compression resistance (Fig. 5a), in a specified interval, processes of intensive peat compaction with a predominance of structural deformations occur. Further, in the area from $50 \mathrm{MPa}$ to $100 \mathrm{MPa}$, values of elastic after-effect $\delta_{V . i}$ decrease. This can be explained by characteristic features of peat particles macrostructure, which ensures their good adhesion in the compaction process. That leads to a decrease in elasticity and predominance of plastic strain component in specified pressures range.

Development of an elastic after-effect in kaolin (Fig. 5b) characterized by a steady increase in its values over the entire range of pressures from 10 to $100 \mathrm{MPa}$. When approximating relationship of $\delta_{V . i}$ and $p_{i}$ for kaolin, the greatest accuracy is achieved by using a power-type equation. Monotonous elastic after-effect increase in kaolin briquettes is probably due to the fact that kaolin microparticles, agglomerated into larger granules, have a lamellar structure, low hardness (2-2.5 on the Mohs scale) and increased plasticity, which positively affects its ability to compact. In this case, conglomerates and particles destruction with an increase of pressure associated with the formation of new contacts, at which elastic residual deformations occur.

Table 4. The results of the approximation of experimental data describing the $\delta_{V}=f(p)$ relation

\begin{tabular}{|l|c|c|}
\hline \multicolumn{1}{|c|}{ Material } & Approximation equation & $R^{2}$ \\
\hline Peat & $\delta_{V}=-0.0021 \times p^{2}+0.2208 p+29.658$ & 0.72 \\
\hline Kaolin & $\delta_{V}=5.5542 \times p^{0.3239}$ & 0.93 \\
\hline Manganese concentrate & $\delta_{V}=5.9776 \times p^{0.1833}$ & 0.82 \\
\hline
\end{tabular}

This can be explained by the fact that particles of manganese concentrate are harder (see Table 2), less prone to fracture, faster to achieve dense packaging, which contributes to a reduction of elastic deformation.

An important characteristic of briquettes, which determines its consumer properties, its density. Therefore, it seems appropriate to use obtained experimental data to assess the influence of elastic after-effect on a value of the final density of briquettes (after relieving the pressure). 
By accordance with experimental data (Table 2), the graphical functions are given in Fig. 6, reflecting the following relationships:

- the density of the briquette under pressure in the mould $\rho_{b r .0}=f(p)$ (see in Table 6);

- the density of the briquette after releasing pressure and extraction from the mould $\rho_{b r: 1}=f(p)$ (see in Table 7).
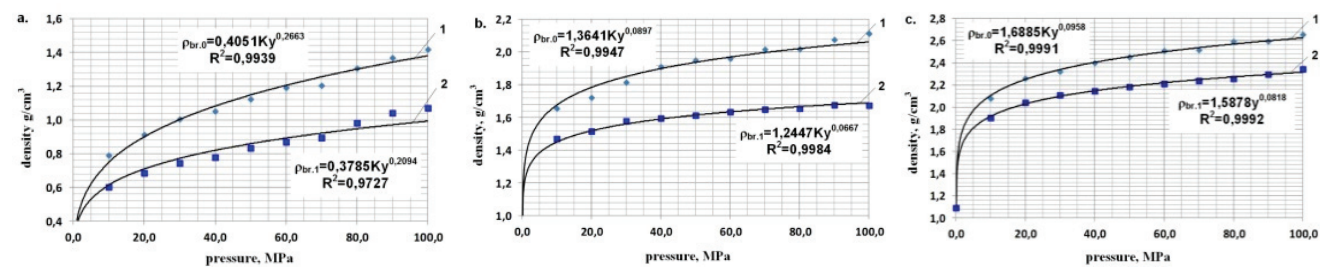

Fig. 6. Dependence of briquette density on pressure: $\mathrm{a}$ - peat, $\mathrm{b}$ - kaolin, $\mathrm{c}$ - manganese concentrate; upper curves - under pressure in the mould, lower curves - after extraction from the mould

Table 5. The results of the approximation of experimental data describing the $\rho_{b r .0}=f(p)$ relation

\begin{tabular}{|l|c|c|}
\hline \multicolumn{1}{|c|}{ Material } & Approximation equation & $R^{2}$ \\
\hline Peat & $\rho_{b r .0}=0.4051 p^{0.2663}$ & 0.99 \\
\hline Kaolin & $\rho_{b r .0}=1.3641 p^{0.0897}$ & 0.99 \\
\hline Manganese concentrate & $\rho_{b r .0}=1.6885 p^{0.0958}$ & 0.99 \\
\hline
\end{tabular}

Table 6. The results of the approximation of experimental data describing the $\rho_{b r .1}=f(p)$ relation

\begin{tabular}{|l|c|c|}
\hline \multicolumn{1}{|c|}{ Material } & Approximation equation & $R^{2}$ \\
\hline Peat & $\rho_{b r .1}=0.3785 p^{0.2094}$ & 0.99 \\
\hline Kaolin & $\rho_{b r .1}=1.2447 p^{0.0667}$ & 0.99 \\
\hline Manganese concentrate & $\rho_{b r .1}=1.5878 p^{0.0818}$ & 0.99 \\
\hline
\end{tabular}

Value of elastic heave (decompaction) defined as a difference in material density under pressure in the mould and after releasing the pressure is described as:

$$
\Delta \rho(p)=\rho_{b r .0}(p)-\rho_{b r .1}(p)
$$

are represented as the relations $\Delta \rho=f(p)$ in Fig. 7 and in Table 7 .

Table 7. The results of the approximation of experimental data describing the $\Delta \rho_{b r}=f(p)$ relation

\begin{tabular}{|l|c|c|}
\hline \multicolumn{1}{|c|}{ Material } & Approximation equation & $R^{2}$ \\
\hline Peat & $\Delta \rho=0.0641 \times \mathrm{p}^{0,3876}$ & 0.99 \\
\hline Kaolin & $\Delta \rho=0.0654 \times \mathrm{p}^{0,405}$ & 0.99 \\
\hline Manganese concentrate & $\Delta \rho=0.0611 \times \mathrm{p}^{0,379}$ & 0.99 \\
\hline
\end{tabular}



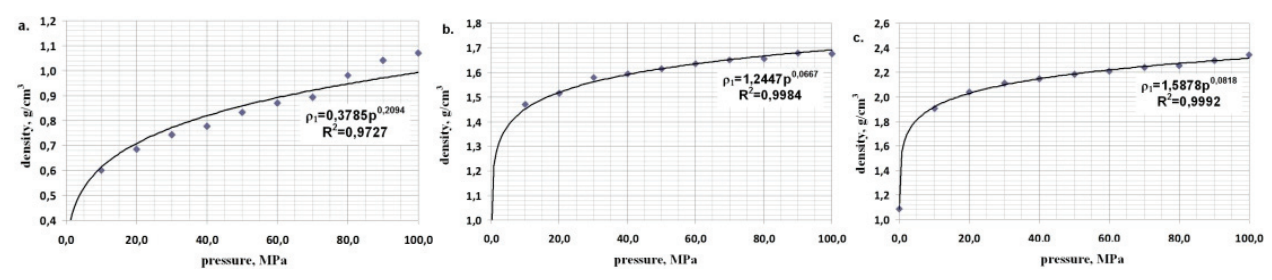

Fig. 7. Dependence of elastic heave (decompaction) of briquettes from pressure: $\mathrm{a}$ - peat, $\mathrm{b}$ - kaolin, $\mathrm{c}$ - manganese concentrate

The functions represented in graphical (Figs. 3-6) and analytical (Tables 5-7) form have a similar view with a briefly less dependence of peat briquettes density in the range of small pressures. The kaolin and manganese concentrate densities show weak dependence from pressure in the range above $60 \mathrm{MPa}$.

\section{CONCLUSION}

In course of studies performed for materials differing in particle hardness, bulk density, humidity, and other characteristics, relationships characterizing their compaction resistance and elastic after-effect have been experimentally constructed and analytically described by approximation functions.

The obtained experimental data for the materials under study and analytical expressions with a sufficient degree of accuracy can be used to study the influence of the configuration of the forming element on the quality of the briquette, taking into account the elastic after-effect.

Further research is aimed at the analysis of other materials and different physical and mechanical properties (moisture, fractions) affecting the compaction process and characterizing the variability of materials at the real mining sites.

\section{ACKNOWLEDGEMENT}

This work is partly supported by EIT RawMaterials GmbH under Framework Partnership Agreements No. 18253 (OPMO- Operation Monitoring of Mineral Crushing Machinery).

\section{REFERENCES}

AL-HAJ IBRAHIM H., ABDULLAH A., 2014, Upgrading delayed petroleum coke fines by the use of pitch binders, Chemical Engineering and Science, Vol. 2, No. 2, 15-17, https://doi.org/10.12691/ ces-2-2-1.

BAYUL K.V., 2012, Effect of the geometrical parameters of roll press forming elements on the briquetting process: analytical study, Powder Metallurgy and Metal Ceramics, Vol. 51, No. 3-4, 157-164, https://doi.org/10.1007/s11106-012-9411-8. 
DAVIES R.M., DAVIES O.A., 2013, Physical and combustion characteristics of briquettes made from water hyacinth and phytoplankton scum as binder, Journal of Combustion, Hindawi Publishing Corporation, Vol. 2013, Article ID 549894, 7 pages, http://dx.doi.org/10.1155/2013/549894.

HENNING C.N., LEOKAOKE N.T., BUNT J.R. WAANDERS F.B., 2018, Testing of briquettes made from witbank coal fines with polyvinyl alcohol as binder, 10th Int. Conference on Advances in Science, Engineering, Technology and Healthcare (ASETH-18), Nov. 19-20, 2018, Cape Town (South Africa).

KHUDYAKOV A.Yu., VASHCHENKO S.V., BAIUL K.V., SEMENOV Yu.S., 2018, Kaolin raw material briquetting for lump chamotte production, Refractories and Industrial Ceramics. Vol. 59 (4), 333-337, https://doi.org/10.1007/s11148-018-0231-3.

KIEUSH L., BOYKO M., KOVERIA A., KHUDYAKOV A., RUBAN A., 2019, Utilization of the prepyrolyzed technical hydrolysis lignin as a fuel for iron ore sintering, Eastern-European Journal of Enterprise Technologies, No. 1/6 (97), 34-39.

KINOSHITA S., YAMAMOTO S., DEGUCHI T., SHIGEHISA T., 2010, Demonstration of upgraded brown coal (UBC) process by 600 tonnes/day plant, KOBELCO Technology Review, No. 29, 93-98.

KRIŽAN P., ŠOOŠ L., VUKELIČ Đ., 2009, A study of impact technological parameters on the briquetting process, Sci. J. Facta Univ., 6, 39-47.

RABINOVICH M.L., 2014, Lignin by-products of soviet hydrolysis industry: resources, characteristics, and utilization as a fuel, Cellulose Chemistry and Technology, Vol. 48, No. 7-8, 613-631.

RAI S., WASEWAR K.L., MUKHOPADHYAY J., YOO C.K. USLU H., 2012, Neutralization and utilization of red mud for its better waste management, Arch. Environ. Sci., 6, 13-33.

RAMACHANDRA RAO S., 2006, Resource recovery and recycling from metallurgical wastes, Waste Management Series, 7, Elsevier B.V., ISBN: 978-0-08-045131-2.

RÖSLER G., LEUCHTENMÜLLER M., ANTREKOWITSCH J., 2016, Possible alternative secondary resources for the production of ferroalloys, XXX microCAD International Multidisciplinary Scientific Conference, University of Miskolc, Hungary, 21-22 April 2016, ISBN 978-963-358-113-1, https://doi.org/10.26649/musci.2016.011.

SWIETOCHOWSKI A., LISOWSKI A., DABROWSKA-SALWIN M., 2016. Strength of briquettes and pellets from energy crops, [in:] Engineering for Rural Development, 547-551.

VASHCHENKO S.V., KHUDYAKOV A.Yu., BAIUL K.V., SEMENOV Yu.S., Selecting the batch composition in briquetting, Steel in Translation, 2018, Vol. 48, No. 8, 509-512, https://doi.org/ 10.3103/S0967091218080132.

ZHDANOV A.V., ZHUCHKOV V.I., DASHEVSKII V.Ya., LEONT'EV L.I., 2015, Problems with waste generation and recycling in the ferroalloys industry, Metallurgist, March 2015, Vol. 58, No. 11-12, 1064-1070, https://doi.org/10.1007/s11015-015-0041-5. 